\title{
Microbial contamination of contact lens cases in the west of Scotland
}

\author{
P Devonshire, F A Munro, C Abernethy, B J Clark
}

\begin{abstract}
A cross-sectional study of $\mathbf{1 7 8}$ asymptomatic contact lens wearers attending 10 contact lens practices in the west of Scotland was conducted over a 4 month period. The aims of the study were to identify specific microbial contaminants in lens cases, to determine the rate of contamination of such containers and to assess the value of the steps involved in different lens care regimens in the prevention of case contamination. Microbial contamination affected $53 \%$ of lens cases. Cases used with conventional wear and disposable systems were contaminated at similar rates and, therefore, the advantage of regular lens replacement may have been lost if these lenses were stored in contaminated cases. Four percent of lens cases were contaminated with amoebal species and all of these showed concomitant bacterial colonisation. These findings imply that case hygiene is probably as important as lens hygiene if new or disinfected lenses are not to be immediatly re-contaminated by storage in dirty cases. Unfortunately simple and effective methods of lens and case disinfection, which would be suitable for use in the average home environment, are not yet available. It follows that frequent and regular disposal of lens cases may prove to be a necessary measure to prevent the build-up of microbial colonisation in such containers.

(Brf Ophthalmol 1993; 77: 41-45)
\end{abstract}

Contact lens wear is widespread bringing with it the serious complication of microbial keratitis. ${ }^{1-5}$ Bacterial keratitis is caused by a wider variety of organisms which are probably opportunistic in nature relying on corneal damage by the contact lens. In contrast, it is believed that Acanthamoeba is a pathogen capable of invading intact corneal epithelium and thus directly initiating infection. ${ }^{6}$ As the lens storage case is a potential source and reservoir of bacteria and amoebae, ${ }^{16-8}$ effective disinfection and clean handling procedures for lenses and their containers are clearly important if keratitis is to be avoided.

Earlier microbiological studies of lens cases have indicated consistently high rates of bacterial contamination ranging from $46 \%$ in California ${ }^{9}$ to $42 \%$ in a comparable study in south west England. ${ }^{10}$ In contrast, the levels of contamination with Acanthamoeba have shown a more marked degree of variation from $7 \%$ in the English study to $0 \%$ in the Californian investigation. No comparable study of lens cases has ever been made in Scotland though there are a few reports of Acanthamoeba keratitis associated with contact lenses in Scotland. ${ }^{112}$ This study was, therefore, undertaken to determine the contamination levels of lens cases in the west of Scotland, to determine the standard of lens case hygiene achieved by patients in this region and to indicate the potential risk of bacterial and amoebic keratitis for those who use contact lenses.

\section{Patients and methods}

Used contact lens cases were collected from patients attending 10 contact lens practices. The patients were resident in Glasgow, Dumbartonshire, north Ayrshire, Renfrewshire, and north Lanarkshire and were recruited voluntarily at review visits to their contact lens practitioner. For inclusion the patients had to attend a practitioner during the study period (1 April 1991 to 31 July 1991) be asymptomatic, and be carrying their cases at the time. Patients fulfilling these criteria were included and there was no attempt to select patients by lens type, care system, wear pattern, indication for lens use, or likelihood of contamination. Patients had no previous knowledge of the study. Their cases were exchanged for new ones and they provided information about their lens care regimen.

All cases and patient data sheets were then numbered and the cases, identified only by code number, were sent to the laboratory. To ensure unbiased processing, the data sheets did not accompany the cases. A total of 178 cases were submitted to the laboratory. In addition, 10 control cases, containing sterile hydrogen peroxide solution, were submitted blind to the laboratory. No organisms were isolated from the control cases.

\section{LABORATORY METHODS}

The cases were opened under aseptic conditions. Where cases consisted of separate compartments for right and left lenses, these compartments were studied independently. Any solution was transferred to a sterile universal container. A sterile cotton neck swab moistened with sterile unpreserved saline was rubbed vigorously over the internal surface of the case and the tip was added to the universal container. This was done even if the case was dry. The universal container was mixed in a vortex mixer for 10 seconds and the contents processed for both bacterial and amoebal contamination.

\section{BACTERIAL ISOLATION}

A $1 \mu$ l loop was used to inoculate solution onto both blood agar and cysteine lactose electrolyte deficient (CLED) plates (Unipath Ltd, Basingstoke). If the case was dry, the swab was used to inoculate the plate. All plates were incubated aerobically at $37^{\circ} \mathrm{C}$ and examined at 24 and 48

Ral Infirmary, Castle Street,

Accepted for publication

17 September 1992 
hours. All coliforms were identified using the API 20E and API 20NE systems (Bio Merieux, Marcy-L'Etoile, France).

\section{AMOEBAL ISOLATION}

One drop of solution from a sterile plastic pipette was used to inoculate each of two non-nutrient agar plates seeded with Escherichia coli. If the case was dry the cotton swab was used to inoculate the centre of the plate. One plate was incubated at $30^{\circ} \mathrm{C}$ and the other at $37^{\circ} \mathrm{C}$. Both plates were examined by low power microscopy every day for 7 days. Identical plates were also inoculated with an Acanthamoeba containing solution to act as a positive control. Amoeba isolates were characterised to genus level according to cyst and trophozoite morphology. ${ }^{13}$

\section{STATISTICS}

Statistical analysis involved the Mann Whitney U test for non-parametric data ${ }^{14}$ or the $\chi^{2}$ test $^{14}$ where appropriate. Where the data precluded the valid use of the $\chi^{2}$ test, the relative risks were estimated. Calculations were carried out using 'Minitab' computer statistical software. Where appropriate, confidence intervals ${ }^{15}$ were calculated using 'Confidence Interval Analysis' computer statistical package.

\section{Results}

\section{CHARACTERISTICS OF STUDY POPULATION}

A total of 178 lens cases were studied: 66 (37\%) belonged to males, $109(63 \%)$ to females and three were unrecorded. The ages of the patients ranged from 8 to 80 years (mean 33 years). Forty six $(26 \%)$ wore rigid lenses and $132(74 \%)$ wore soft lenses.

The types of lens cases included 'baskets' $(\mathrm{n}=105,59 \%)$, 'cups' $(\mathrm{n}=55,31 \%)$ and 'others' $(n=11,6 \%)$. Seven $(4 \%)$ case types were unrecorded. The associated lenses were used in conventional daily wear $(n=87,48.9 \%)$, standard extended wear $(n=1,0.6 \%)$, disposable $(n=52,29 \%)$, and planned replacement $(n=38$, $21 \cdot 5 \%)$ systems.

The methods of contact lens care hygiene included disinfection by 'chemical' means

Table 1 Comparison of the ages of lens cases from patients with either contaminated or sterile cases

\begin{tabular}{llc}
\hline Age of lens case (months) & Contaminated & Sterile \\
\hline Number & 91 & 82 \\
Median & 6 & $5 \cdot 5$ \\
[interquartile range] & {$[3-17]$} & {$[2-13]$} \\
\hline
\end{tabular}

$\mathrm{W}=6420,0.01<\mathrm{p}<0.05 ; 95 \%$ confidence interval of difference between medians is 0.001 to 3.501 . The interquartile range is that between the lst and 3rd quartiles.

Table 2 Comparison of the age of lenses from patients with either contaminated or sterile cases

\begin{tabular}{llc}
\hline Age of lens (months) & Contaminated & Sterile \\
\hline Number & 87 & 77 \\
Median & 3 & 2 \\
[interquartile range] & {$[1-18]$} & {$[0 \cdot 5-6]$} \\
\hline
\end{tabular}

$\mathrm{W}=7885,0.01<\mathrm{p}<0.05 ; 95 \%$ confidence interval of difference between medians is 0.002 to 2.499 .
( $n=74,42 \%)$, hydrogen peroxide $(n=39,22 \%)$, chlorine $(n=54,30 \%)$, a chlorhexidine tablet in tapwater system ('Optimeyes,' Bausch \& Lomb, $n=6,3 \%)$, and heat $(n=1,0.6 \%)$. In four cases the method was unrecorded. Rinsing solutions included aerosol saline $(\mathrm{n}=109,61 \%)$, distilled water $(n=4,2 \%)$, home made saline solutions $(n=4,2 \%)$, and 'others' $(n=26,15 \%)$ which included tapwater and preserved saline. In 35 $(20 \%)$ cases the method was unrecorded. Forty four $(25 \%)$ patients specifically admitted to using unmodified tapwater in the lens care process, 71 patients $(40 \%)$ used enzyme preparations, and $134(75 \%)$ used surfactant cleansers during lens hygiene.

\section{MICROBIAL CONTAMINATION OF CONTACT LENS} CASES

At least one contaminating organism was detected in $95(53 \%)$ of the contact lens cases studied. Where separate right and left lens compartments were studied, both sides always yielded identical organisms. For numerical analyses these cases are regarded as single specimens.

The relationship between the age of the contact lens case and the presence of microbial contamination is shown in Table 1 . There is a significant difference between the ages of contaminated and sterile lens cases; contaminated cases are likely to be older than sterile cases.

The relationship between the age of the contact lenses normally stored in the cases and microbial contamination is shown in Table 2 . There is a significant difference between the ages of the contact lenses stored in contaminated and sterile lens cases with older lenses more likely to come from contaminated cases.

Table 3 shows that the time interval between changing the lens case solution and collecting the case was significantly longer in the contaminated than in the sterile group.

Thirty six (54\%) cases belonging to males were

Table 3 Comparison of the time elapsed since solution in case last changed in patients with either contaminated or sterile cases

\begin{tabular}{llc}
\hline $\begin{array}{l}\text { Time since solution last changed } \\
\text { (hours) }\end{array}$ & Contaminated & Sterile \\
\hline Number & 89 & 80 \\
Median & 12 & 12 \\
[interquartile range $]$ & {$[10-34]$} & {$[6-18]$} \\
\hline
\end{tabular}

$\mathrm{W}=8304,0.01<\mathrm{p}<0.05 ; 95 \%$ confidence interval of difference between medians is 0.001 to 8.000 .

Table 4 Comparison of the lens types, case types, and modes of lens use in patients with either contaminated or sterile cases

\begin{tabular}{llll}
\hline & & Contaminated & Sterile \\
\hline Lens type & Rigid lenses & $36(78 \%)$ & $10(22 \%)$ \\
Case type† & Soft lenses & $59(45 \%)$ & $73(55 \%)$ \\
& Basket & $56(53 \%)$ & $49(47 \%)$ \\
Mode of & Cup and others & $36(54 \%)$ & $30(46 \%)$ \\
use $\neq$ & Non-disposable & $50(57 \%)$ & $38(43 \%)$ \\
& Disposable & $22(42 \%)$ & $30(58 \%)$ \\
& Planned replacement & $23(60 \%)$ & $15(40 \%)$ \\
\hline
\end{tabular}

${ }^{\star} \chi^{2}=15 \cdot 4, \mathrm{df}=1, \mathrm{p}<0.001$. Difference in proportions $=33 \%$; $95 \%$ confidence interval for difference in proportion is $19 \%$ to $48 \%$.

$+\chi^{2}=0.024, \mathrm{df}=1, \mathrm{p}>0.50$. Difference in proportions $=1.2 \%$ $+\chi^{2}=0.024, \mathrm{df}=1, \mathrm{p}>0.50$. Difference in proportions $=1.2 \%$;
$95 \%$ confidence interval for difference in proportion is $-17 \%$ to $14 \%$. $\mp \chi^{2}=3 \cdot 76, \mathrm{df}=2, \mathrm{p}>0 \cdot 10$. 
Table 5 Comparison of the modes of contact lens hygiene in patients with either contaminated or sterile cases

\begin{tabular}{|c|c|c|c|}
\hline & & Contaminated & Sterile \\
\hline Use of enzyme ${ }^{\star}$ & Ensyme used & $39(55 \%)$ & $32(45 \%)$ \\
\hline \multirow{2}{*}{ Use of surfactant $†$} & $\begin{array}{l}\text { Ensyme free } \\
\text { Surfactant used }\end{array}$ & $\begin{array}{l}56(52 \%) \\
69(52 \%)\end{array}$ & $\begin{array}{l}51(48 \%) \\
65(48 \%)\end{array}$ \\
\hline & $\begin{array}{l}\text { Surtactant used } \\
\text { Surfactant free }\end{array}$ & $\begin{array}{l}69(52 \%) \\
26(59 \%)\end{array}$ & $\begin{array}{l}65(48 \%) \\
18(41 \%)\end{array}$ \\
\hline \multirow[t]{2}{*}{ Rinsing solution $\ddagger$} & Aerosol saline & $55(50 \cdot 5 \%)$ & $54(49 \cdot 5 \%)$ \\
\hline & $\begin{array}{l}\text { Distilled water } \\
\text { Home made saline and others }\end{array}$ & $\begin{array}{r}2(50 \%) \\
21(70 \%)\end{array}$ & $\begin{array}{l}2(50 \%) \\
9(30 \%)\end{array}$ \\
\hline \multirow[t]{7}{*}{ Disinfection } & Hydrogen peroxide & $13(33 \%)$ & $26(67 \%)$ \\
\hline & Chemical & $40(54 \%)$ & $34(43 \%)$ \\
\hline & Chlorine & $\begin{aligned} & 40(74 \%) \\
& 0(0 \%)\end{aligned}$ & $\begin{array}{c}14(26 \%) \\
6(100 \%)\end{array}$ \\
\hline & $\begin{array}{l}\text { Heat } \\
\text { Hexiane in tapwater }\end{array}$ & $0(0 \%)$ & $1(100 \%)$ \\
\hline & & Relative risk & $\begin{array}{l}95 \% \text { Confidence } \\
\text { interval) }\end{array}$ \\
\hline & Hydrogen peroxide & 15 & - \\
\hline & $\begin{array}{l}\text { Chemical } \\
\text { Chlorine }\end{array}$ & $\begin{array}{l}1 \cdot 62 \\
2 \cdot 22\end{array}$ & $\begin{array}{l}(0.99 \text { to } 2.65) \\
(1.39 \text { to } 3.56)\end{array}$ \\
\hline
\end{tabular}

$\chi^{2}=0 \cdot 115, \mathrm{df}=1, \mathrm{p}>0.05$. Difference in proportions $=2 \cdot 6 \% ; 95 \%$ confidence interval of difference in proportion is $-12 \%$ to $18 \%$.

$+\chi^{2}=0.77, d f=1, p>0.05$. Difference in proportions $=7 \cdot 6 \% ; 95 \%$ confidence interval of difference in proportion is $-9 \%$ to $24 \%$.

$\mp$ Combining aerosol saline with distilled water for calculation due to similar rates, $\chi^{2}=3 \cdot 657, \mathrm{df}=1$, p $>0.05$. Difference in proportions $=19 \cdot 6 \% ; 95 \%$ confidence interval for difference in proportion is $0.7 \%$ to $38 \%$.

\Hydrogen peroxide, having the lowest observed contamination rate, has a risk arbitrarily defined as unity to allow comparison of relative risks (the referent).

contaminated, whereas $56(51 \%)$ cases belonging to females were contaminated. There is no significant difference between the contamination rates of cases belonging to males and females $\left(\chi^{2}=0 \cdot 17, \mathrm{df}=1, \mathrm{p}>0 \cdot 50\right.$, difference of proportions $=3 \%, 95 \%$ confidence interval for difference between proportions are $-12 \%$ to $18 \%$ ).

Table 4 shows the relationships between contact lens type, case type, mode of lens use, and microbial contamination. There is a significant relationship between type of lens (rigid or soft) and contamination - the cases of rigid lens users being more frequently contaminated. However, there is no apparent relationship between the case structure, or the system of contact lens use (disposable lenses or not), with the presence of contaminating micro-organisms in the contact lens cases.

Table 5 shows the relationships between components of the differing care regimens and microbial contamination of the lens case. When tested in isolation, the use of enzyme preparations or surfactant cleansers bear no relation to lens case sterility. Similarly, there is no evidence that the solution used for lens rinsing after disinfection bears any relation to microbial contamination. However, lens cases cleaned with chlorine-based disinfectants seemed more susceptible to contamination than those treated with hydrogen peroxide. Other chemical disinfecting methods had a similar relative risk of contamination to peroxide disinfection. Too few of our samples employed heat or chlorhexidine in tapwater (Optimeyes) disinfection to make meaningful comparisons. It should be emphasised, however, that most methods of disinfection, as used by this sample of contact lens wearers, failed to produce high rates of lens case disinfection.

\section{CONTAMINATION OF CONTACT LENS CASES BY AMOEBAE}

Seven contact lens cases (4\%) were contaminated by amoebae - six by Acanthamoeba species and one by Hartmanella species. All seven belonged to soft contact lens wearers. Six contaminated cases
Table 6 Microbial contaminants from the cases of hard contact lenses

\begin{tabular}{lc}
\hline Organism & $\begin{array}{l}\text { No of cases } \\
\text { contaminated (\%) }\end{array}$ \\
\hline Serratia marcescens & $14(30 \cdot 4)^{\star}$ \\
Pseudomonas fluorescens & $10(21 \cdot 7)^{\star}$ \\
Serratia liquifaciens & $9(19 \cdot 6)$ \\
Escherichia coli & $6(13)^{\star}$ \\
Klebsiella pneumoniae & $4(8 \cdot 7)^{\star}$ \\
Alcaligenes denitrificans & $3(6 \cdot 5)$ \\
Enterobacter agglomerans & $2(4 \cdot 3)$ \\
Achromobacter & $2(4 \cdot 3)$ \\
Serratia odorifera & $1(2 \cdot 2)$ \\
Klebsiella oxytoca & $1(2 \cdot 2)$ \\
Enterobacter cloacae & $1(2 \cdot 2)$ \\
Yersinia intermedia & $1(2 \cdot 2)$ \\
\hline Some contact lens cases were contaminated by more than one \\
organism, therefore, more isolates are enumerated than the actual \\
number of cases contaminated. \\
$\star$ Organisms recognised as potentially pathogenic in the eye. ${ }^{\mid \star}$
\end{tabular}

were of the basket type and the remaining case type was unrecorded. Amoebae contaminated the cases of standard wear (three cases), disposable (two cases), and planned replacement (two cases) systems. The mode of disinfection for all seven was chlorine, and the rinsing solutions used were aerosol saline (five cases) and home made saline (one case) - the rinsing solution of one case was unrecorded. Three cases belonged to users of enzyme preparations and five cases belonged to users of surfactant cleansers. None of these patients admitted to the use of unmodified tapwater in the lens care process.

\section{CONTAMINANTS OF THE CASES OF RIGID CONTACT LENS WEARERS}

Forty six patients wore rigid contact lenses, 44 wore gas permeable, and two wore poly(methylmethacrylate) lenses. Thirty six (78\%) of these cases were contaminated and a wide variety of organisms were isolated (Table 6). At least one isolate recognised as potentially pathogenic to the cornea was found in $19(41 \%)$ of these contact lens cases. ${ }^{16}$

\section{CONTAMINANTS OF THE CASES OF SOFT CONTACT LENS WEARERS}

Of the 132 patients wearing soft contact lenses, $40(30 \%)$ used low water content lenses, 34 (26\%) used medium, and $58(44 \%)$ used high. Fifty nine ( $45 \%)$ cases were contaminated and, as with the cases of rigid contact lens wearers, a wide variety of organisms were isolated (Table 7). At least one potentially pathogenic organism was isolated from 33 (25\%) cases of soft contact lens users. ${ }^{16}$

Acanthamoeba was always isolated with at least one bacterial co-contaminant which included Enterobacter agglomerans, Flavobacterium indologenes, Pseudomonas fluorescens, Serratia marcescens and Klebsiella pneumoniae.

\section{Discussion}

Microbial keratitis is a potentially sightthreatening complication of contact lens wear..$^{217}$ However, owing to the undoubted popularity of contact lenses efforts must be made to prevent it. Although rare it may affect as many as 12000 new cases annually throughout the United 
Table 7 Microbial contaminants from the cases of soft contact lenses

\begin{tabular}{|c|c|}
\hline Organism & $\begin{array}{l}\text { No of cases } \\
\text { contaminated (\%) }\end{array}$ \\
\hline $\begin{array}{l}\text { Acinetobacter calcoaceticus var lwoffi } \\
\text { Klebsiella pneumoniae } \\
\text { Serratia liquifaciens } \\
\text { Enterobacter agglomerans } \\
\text { Pseudomonas maltophilia } \\
\text { Acanthamoeba species } \\
\text { Klebsiella oxytoca } \\
\text { Serratia marcescens } \\
\text { Pseudomonas acidovorans } \\
\text { Enterobacter cloacae } \\
\text { Pseudomonas fluorescens } \\
\text { Diphtheroids } \\
\text { Alcaligenes denitrificans } \\
\text { Flavobacterium indologenes } \\
\text { Pseudomonas aeruginosa } \\
\text { Pseudomonas testosteroni } \\
\text { Flavobacterium multivorum } \\
\text { Serratia plymuthica } \\
\text { Micrococcus } \\
\text { Yeast species } \\
\text { Escherichia coli } \\
\text { Enterobacter aerogenes } \\
\text { Flavobacterium meningosepticum } \\
\text { Flavobacterium species } \\
\text { Pseudomonas picketti } \\
\text { Pseudomonas luteola } \\
\text { Pseudomonas paucimobilis } \\
\text { Bacillus species } \\
\text { Agrobacterium radiobacter } \\
\text { Vibrio metschnikovii } \\
\text { Staphylococcus epidermidis } \\
\text { Moraxella phenylpyruvia } \\
\text { Pasteurella species } \\
\text { Yersinia enterocolitica } \\
\text { Hartmanella species } \\
\text { Citrobacter freundii }\end{array}$ & 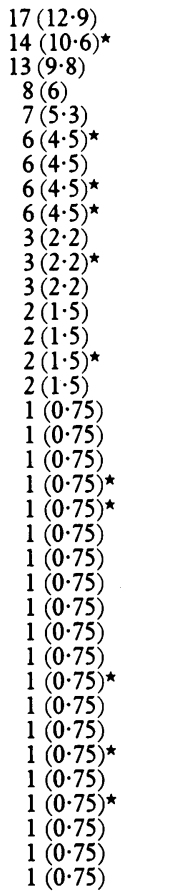 \\
\hline
\end{tabular}

Some contact lens cases were contaminated by more than one organism, therefore, more isolates are enumerated than the actua number of cases contaminated.

$\star$ Organisms recognised as potentially pathogenic in the eye. ${ }^{16}$

States. ${ }^{17}$ In public health terms, therefore, it is a sizeable potential cause of loss of visual acuity. There is disagreement as to which factors contribute to the risk of developing microbial keratitis. It is widely agreed that the wearing of contact lenses for extended periods contributes significantly to risk ${ }^{1517-20}$ but the relationship to lens hygiene has been questioned recently. ${ }^{3-5}$ Nevertheless, there is good evidence to suggest that the organisms responsible for contact lens associated keratitis differ from those of noncontact lens associated keratitis ${ }^{34}$ and that they can be isolated from components of the contact lens care system. ${ }^{16-8122122}$ Studies of the care regimen use and associated contamination rates of lens storage cases are, therefore, valuable in assessing the potential for reducing the risk of microbial keratitis.

Previous studies of microbial contamination of contact lens cases in the United States ${ }^{93-25}$ and the United Kingdom ${ }^{102}$ have demonstrated disturbingly high rates of contamination whilst restricting their sample populations in size, type of lens used, and practice or hospital attended. This study is the first, to our knowledge, to derive a relatively large sample population of contact lens users that includes disparate patterns of use, methods of care, and a large number of overseeing contact lens practitioners. It is, therefore, likely to be more representative of the overall population of contact lens wearers in our area. In addition, not all previous studies looked for amoebal contamination of contact lens cases.

The overall contamination rate of cases in our study is $53 \%$ and comparable to that of Donzis et $a l^{9}$ and Larkin et al. ${ }^{10}$ We show that con- taminated cases, and the lenses stored in them, are likely to be older than sterile cases. This supports the theory that reducing both case and lens lifetime may help to reduce contamination $^{10246}$ and that attention to storage case hygiene, in addition to lens hygiene, is important in preventing accumulation of a microbial reservoir within the case $\mathrm{e}^{2022}{ }^{24-26}$ capable of immediately recontaminating a sterile lens. ${ }^{27}$

Males are more frequently affected by keratitis $^{51728}$ than females and it has been suggested that this may represent relative disregard of hygiene practices by males. Our data, however, demonstrate that there is no difference between the contamination rates of cases belonging to males and females and, therefore, we cannot conclude that the standard of hygiene practised by males is inferior to that of females.

Our observation that conventional and disposable systems had similar rates of case contamination is of particular interest in that one of the perceived advantages of frequent lens renewal is a reduced risk of inoculating the eye with adherent pathogens. However, cases of microbial keratitis in users of disposable lenses continue to be reported. ${ }^{121}{ }^{29}$ Clearly, the storage of a disposable lens in a dirty case may contaminate the lens and negate, to some extent, the advantage of using a disposable lens.

The use of chlorine for disinfection rather than hydrogen peroxide was associated with a modest increase in the relative risk of contamination of the lens storage case. The use of other chemicals than hydrogen peroxide was not associated with any increase in relative risk of case contamination. Too few subjects in our sample used heat or chlorhexidine tablets in tapwater to allow mean ingful analysis. There was no significant relationship between the use of enzyme or surfactant preparations and successful disinfection of the lens case. Similarly, there were no significan patterns in the type of rinsing solution used and the presence of contamination in the lens case. It is noteworthy that, in this sample of contact lens users, most methods of care were associated with lens case contamination. Thus, whilst available methods of lens care are capable of successful decontamination of lenses, ${ }^{30-34}$ in the hands of many patients they are used suboptimally or inappropriately ${ }^{72023}$ and have not proved successful in lens case disinfection in our sample. Even when reinforcement of good hygiene methods successfully reduces the proportion of cases contaminated, ${ }^{24}$ a considerable proportion of patients retain microbial contamination.

The finding that Acanthamoeba species contaminate lens cases in Scotland at a similar rate as elsewhere in the United Kingdom ${ }^{10}$ is of note. In comparison to other countries there have been relatively few reported cases of Acanthamoeba in Scotland. ${ }^{112}$ The reasons for this are unclear. Our results suggest that contact lens users in Scotland should be at a similar risk of infection as patients elsewhere. It is interesting that all isolates were from cases of soft contact lens users and that all used chlorine based disinfection regimens, though the numbers isolated preclude formal analysis and cannot be used to incriminate any care system. Amoebae contaminated lens cases from systems employing standard wear of 
lenses and those using disposal of lenses. Thus, regular replacement of lenses does not necessarily remove the risk of inoculating the eye with amoebae, and Acanthamoeba keratitis has been described in users of disposable type lenses. ${ }^{121} 29$ All amoebal contaminated lens cases also contained bacterial co-contaminants, a state which may be advantageous to the organism by providing a nutrient source. ${ }^{102235}$ The source of amoebal contaminants in our population is uncertain. Whilst $25 \%$ of our sample population admitted to the use of unmodified tapwater in their lens care process, this did not include any of the patients with amoebal contamination. One patient, however, did use a home-made saline solution, a method reported to predispose to amoebal infection. ${ }^{828}$ It is possible that amoebal contamination occurred in the bathroom environment without direct use of water as this has recently been shown to contain amoebae in dust around washbasins. ${ }^{22}$

In conclusion, large number of asymptomatic contact lens wearers carry significant microbial contamination of their lens storage cases. The contaminants include both pathogens and nonpathogens but, in our population, Acanthamoeba are present as frequently as many other recognised pathogens. Most care regimens represented in our population were affected by contamination. We suggest that the complexities of current care regimens, whilst capable of good disinfection, are relatively clumsy and ineffective in a large proportion of contact lens wearers, placing them at risk of microbial keratitis. More attention should be given to good hygiene methods for lens storage cases, in addition to the lenses themselves, in order to reduce their potential for harbouring pathogenic organisms. To enhance patient compliance, the availability of simple one step care regimens capable of both lens and case disinfection in the hands of the average contact lens user are required. As a simple adjunct these may include frequent disposal of storage cases to reduce the risk of microbial contamination.

We thank the staff of the contact lens clinic at Glasgow Eye Infirmary for allowing us access to their patients and helping in the collection of the lens cases. We are also indebted to Professor $\mathrm{K}$ Vickerman FRS for his help in the identification of amoebal isolates. We thank Dr D A R Simmons for his helpful comments on this manuscript. We are grateful to $P$ Breeze and $L$ Harkins for their invaluable statistical expertise.

1 Mondino BJ, Weissman BA, Farb M, Pettit TH. Corneal ulcers associated with daily-wear and extended-wear contact lenses. Am 7 Ophthalmol 1986; 102: 58-65.

2 Chalupa E, Swarbrick H, Holden BA, Sjostrand J. Severe corneal infections associated with contact lens wear. Corneal infections associated

3 Dart JKG. Bacterial keratitis in contact lens users. $B M \mathcal{F}$ 1987; 295: 959-60.

4 Dart JKG. Predisposing factors in microbial keratitis: the significance of contact lens wear. Br $\mathcal{F}$ Ophthalmol 1988; 72: 926-30.
5 Dart JKG, Stapleton F, Minassian D. Contact lenses and other risk factors in microbial keratitis. Lancet 1991; 338: 650-3. 6 Moore MB. Acanthamoeba keratitis and contact lens wear: the patient is at fault. Cornea 1990; 9 (Suppl 1): S33-5.

7 Golden B, Fingerman LH, Allen HF. Pseudomonas corneal ulcers in contact lens wearers. Arch Ophthalmol 1971; 85: ulcers

8 Wilson LA, Schlitzer RL, Ahearn DG. Pseudomonas corneal ulcers associated with soft contact lens wear. Am $\mathcal{F}$ Ophthal mol 1981; 92: 546-54

9 Donzis PB, Mondino BJ, Weissman BA, Bruckner DA Microbial contamination of contact lens care systems. Am f Ophthalmol 1987; 104: 325-33.

10 Larkin DFP, Kilvington S, Easty DL. Contamination of contact lens storage cases by Acanthamoeba and bacteria. Brf Ophthalmol 1990; 74: 133-5.

$11 \mathrm{Gibb}$ AP. Acanthamoeba keratitis. Communicable Diseases Scotland weekly report 1989; 29: 4 .

12 Williamson TH, Devonshire P, Seal DV, Kirkness CM. A multiresistant strain of Acanthamoeba in a disposable contact lens wearer (in preparation)

13 Page FC. A new key to freshwater and soil gymnamoebae. Freshwater Biological Association, Ambleside, UK, 1988 14 Bland M, An introduction to medical statistics. Oxford: Oxford University Press, 1987.

15 Gardner MJ, Altman DG. Statistics with confidence - confidence intervals and statistical guidelines. London: BMJ Books, 1989

6 McDonnel PJ, Green WR. Keratitis. In: Mandell GL, Dougla RG, Bennett JE, eds. Principles and practice of infectious diseases, 3rd ed. New York: Churchill Livingstone, 1990 982.

17 Poggio EC, Glynn RJ, Schein OD, Seddon JM, Shannon MJ, Scardino VA, et al. The incidence of ulcerative keratitis among users of daily-wear and extended-wear soft contact lenses. N Engl F Med 1989; 321: 779-83.

18 Cohen EJ, Laibson PR, Arentsen JJ, Clemons CS. Corneal ulcers associated with cosmetic extended-wear soft contact lenses. Ophthalmology 1987; 94: 109-13.

19 Franks WA, Adams GGW, Dart JKG, Minassian D. Relative risks of different types of contact lenses. BMF 1988; 297: 524-5.

20 Schein OD, Glynn RJ, Poggio EC, Seddon JM, Kenyon KR The relative risk of ulcerative keratitis among users of dailywear and extended-wear soft contact lenses. $N \mathrm{Engl} \mathcal{F} \mathrm{Med}$ 1989; 321: 773-8.

21 Heidemann DG, Verdier DD, Dunn SP, Stamler JF Acanthamoeba keratitis associated with disposable contact lenses. Am f Ophthalmol 1990; 110: 630-4.

22 Seal D, Stapleton F, Dart J. Possible environmental sources of Acanthamoeba spp in contact lens wearers. Br $\mathcal{F}$ Ophthalmol 1992; 76: 424-7

23 Pitts RE, Krachmer JH. Evaluation of soft contact lens disinfection in the home environment Arch Ophthalmol 1979; 97: 470-2.

24 Wilson LA, Sawant AD, Simmons RB, Ahearn DG. Microbia contamination of contact lens storage cases and solutions Am $\mathcal{F}$ Ophthalmol 1990; 110: 193-8.

25 Simmons PA, Edrington TB, Hsieh L, Wang L. Bacteria contamination rates of soft contact lens cases. Int Contact Lens Clin 1991; 18: 188-91.

26 McKenny CD, Ajello M. Comparative case contamination: three disinfection systems. Int Contact Lens Clin 1991; 18 14-20.

27 John T, Desai D, Sahm D. Adherance of Acanthamoeba castellanii cysts and trophozoites to unworn soft contact castellanii cysts and trophozoites to unworn

28 Stehr-Green JK, Bailey TM, Visvesvara GS. The epidemiology of Acanthamoeba keratitis in the United States. logy of Acanthamoeba keratitis

29 Ficker L, Hunter P, Seal D, Wright P. Acanthamoeba keratitis occurring with disposable contact lens wear. Am $\mathcal{F}$ Ophthalmol 1989; 108: 453 .

30 Bernstein HN, Stow MN, Maddox Y. Evaluation of the 'aseptization' procedure for the soflens hydrophilic contac lens. Can f Ophthalmol 1973; 8: 575-6.

31 Tragakis MP, Brown SI, Pearce DB. Bacteriologic studies of contamination associated with soft contact lenses. Am F Ophthalmol 1973; 75: 496-9.

32 Morgan JF. Complications associated with contact lens solutions. Ophthalmology 1979; 86: 1107-19.

33 Ludwig IH, Meisler DM, Rutherford I, Bican FE, Langston RHS, Visvesvara GS. Susceptibility of Acanthamoeba to soft contact lens disinfection systems. Invest Ophthalmol Vis Sci 1986; $27: 626-8$.

34 Nauheim RC, Brockman RJ,Stopak SS, Turgeon PW, Keleti $\mathrm{G}$, Roat MI, et al. Survival of Acanthamoeba in contact lens rinse solutions. Cornea 1990; 9: 290-3.

35 Larkin DFP, Easty DL. External eye flora as a nutrient source for Acanthamoeba. Graefes Arch Clin Exp Ophthalmol 1990 228: $458-60$. 